\title{
One Novel Zn(II) Nitro-containing Metal Organic Framework for Dye-Adsorption and Photo Degradation
}

\author{
Weiqi $\mathrm{Li}^{1}$, Xieao $\mathrm{Du}^{1}$, Haiyan $\mathrm{He}^{\mathrm{i}^{*}}$ \\ ${ }^{1}$ College of Mechanics and Materials, Hohai University, Nanjing, Jiangsu, 210098, China
}

*Corresponding Author: H.Y. He; West Focheng Road No. 8, Hohai University, Nanjing, Jiangsu, 210098, China; email address: he.haiyan@hhu. edu.cn

\begin{abstract}
:
A novel metal-organic framework $\left[\mathrm{Zn}_{0.5}\left(\mathrm{~L}_{1}\right)\left(4,4^{\prime}-\mathrm{Bpy}\right)_{0.5}\right]$, (HU21, HU for Hohai University, $\mathrm{L}_{1}=$ 4-hydroxy-3-nitrobenzoic acid, 4,4'-bipyridine $=4,4^{\prime}$-Bpy), has been isolated through hydro-thermal reaction. Single-crystal X-ray diffraction reveals the compound features a $1 \mathrm{D}$ fishbone-like chain. A fast adsorption rate of methylene blue with HU21 was observed in the dark, but under irritation the degradation rate of the dye was obviously increased. The degradation of methylene blue dye reached $248 \mathrm{mg} / \mathrm{g}$ under light irritation, and the photocatalytic activity reached $96.1 \%$. Keywords: Metal organic frameworks; Hydrothermal reaction; Photocatalyst; Dye adsorption;

Citation: W.Q. Li, X.A. Du, H.Y. He, One Novel Zn(II) Nitro-containing Metal Organic Framework for Dye-Adsorption and Photo Degradation. Res Appl Mat Sci, 2019,1(1): 39-44. https://doi.org/10.33142/msra.v1i1.672
\end{abstract}

\section{Introduction}

In the past decades, environmental pollution has become more and more serious, especially the pollution of water resources. If it is allowed to continue to develop, it will endanger the survival of human beings, so the treatment of water pollution must arouse human attention. In the past, there were mainly physical, chemical and biological methods in water pollution treatment. Physical method is cheaper, but the treatment effect is poor. Chemical treatment is effective, but the price is high. Biological process usually takes a lot of time and other microorganisms to treat wastewater, and the space occupied in the process of treatment is also a waste of space. Therefore, in the treatment of sewage, it is often not a single method, but a combination of various methods. Recently, a new kind of material, metal-organic skeleton, has come into people's vision. Since the emergence of organometallic skeleton, it has attracted the attention of many researchers. Metal atoms and organic ligands in MOFs are bound by coordination bonds, and different ligands are bound by covalent bonds, so that metal atoms and organic ligands can be linked into chains and finally form skeleton structures. Because of its large specific surface area, adjustable pore size and structure, MOFs can also have various properties by replacing metal ions. ${ }^{[1-3]}$ At present, MOFs have good applications in gas adsorption, drug sustained release and supercapacitors. ${ }^{[4-7]}$ The pore size of MOFs can be adjusted by replacing larger similar ligands or using structural regulators when materials with smaller pore size are obtained. ${ }^{[8,9]}$ Because of this property of MOFs, MOFs can be used as dye adsorbents. Luo et al. constructed a kind of Zn-MOFs, which can absorb anodic dyes. ${ }^{[10]}$ Chen et al. has constructed a series of MOFs based on lanthanide metals, which have high adsorption rates for dye molecules. ${ }^{[1]]}$ Yan et al. constructed three kinds of Co-MOF for adsorbing cationic dyes, and the integrity of the skeleton was not destroyed after adsorption. ${ }^{[12]}$ ZN-MOF constructed by Zhang et al. has good adsorption capacity for MB because of its suitable pore size. ${ }^{[13]}$ By adjusting their structure, they can absorb larger or different dyes. Zha et al. By introducing highly branched alkanes, the modified MOFs adsorbed 99\% Rhodamine 6G, while the original MOFs only adsorbed $52 \%{ }^{[14]} \mathrm{Xu}$ et al. synthesized a composite material on the basis of ZIF- 8 , and its adsorption rate of methyl violet was greatly improved. ${ }^{[15]}$ However, not all MOFs have large channels, so the adsorption of organic dyes by these MOFs mainly makes them immobilized on the surface of MOFs. Han et al. constructed a new type of MOFs, which adsorbed Congo red by hydrogen bond and electrostatic interaction. ${ }^{[16]}$ But this way of adsorbing organic dyes will face the problem of easy desorption. Later, it was found that MOFs exhibited good photocatalytic activity under ultraviolet and LED light. Luo et al. constructed two kinds of Zn-MOF, which showed excellent catalytic activity for methyl orange, methylene blue and Rhodamine $\mathrm{B}$ under UV irradiation. ${ }^{[17]} \mathrm{A}$ binuclear Co-MOF constructed by Xiao et al. has photocatalytic activity on RhB under UV irradia- 
tion. ${ }^{[18]}$ The porous structure of MOFs enables active sites to be exposed to a greater extent, thus making the contact between reactants and active sites easier. MOFs have properties similar to semiconductors, so under the action of light, MOFs can produce electrons and holes, which can catalyze redox reaction. When MOFs are used to adsorb photocatalytic dyes, the essence is that MOFs generate electrons and holes under photocatalytic conditions. These electrons and holes catalyze the reduction of $\mathrm{O}_{2}$ to $\cdot \mathrm{O}^{2-}$, then $\cdot \mathrm{O}^{2-}$ is converted to $\cdot \mathrm{OH}$, and $\cdot \mathrm{OH}$ can decompose organic dyes into $\mathrm{CO}_{2}$ and $\mathrm{H}_{2}{ }^{\left[{ }^{[19-21]}\right.}$ Based on this principle, Xiao et al. studied the effect of external catalyst $\mathrm{H}_{2} \mathrm{O}_{2}$ on photocatalysis, and made good progress. ${ }^{[22]}$

In this paper, we present the synthesis of one novel zincbased metal organic framework HU21 $\left[\mathrm{Zn}_{0.5}\left(\mathrm{~L}_{1}\right)(4,4 \text { '-Bpy })_{0.5}\right]$, single-crystal X-ray diffraction reveals that the complex features one-dimensional fishbone chains and finally three-dimensional superamolecular structure. This $\mathrm{Zn}-\mathrm{MOF}$ compound displays interesting dye adsorption and photocatalytic performance. The degradation of methylene blue dye reached $248 \mathrm{mg} / \mathrm{g}$ under light irritation, and the photocatalytic activity reached $96.1 \%$.

\section{Experimental section}

\subsection{Materials and Synthesis}

All medicines were used directly after commercial purchase without further purification.

Synthesis of HU21 $\left[\mathrm{Zn}_{0.5}\left(\mathrm{~L}_{1}\right)(\mathbf{4 , 4} \text { '-Bpy })_{0.5}\right]$ : A mixture of $20 \mathrm{mg}$ of $\mathrm{Zn}\left(\mathrm{NO}_{3}\right)_{2} \cdot 6 \mathrm{H}_{2} \mathrm{O}, 10 \mathrm{mg}$ of 4-hydroxy-3-nitrobenzoic acid $\left(\mathrm{L}_{1}\right)$ and $5 \mathrm{mg}$ of 4,4'-bipyridine (4,4'-Bpy) was suspended in $5 \mathrm{ml}$ distilled water, and heated in a teflon-lined steel bomb at $120^{\circ} \mathrm{C}$ for 48 hours. The resulting colorless crystals were collected and dried at $50^{\circ} \mathrm{C}$ (yield: $57 \%$ ). The synthesis of HU21 formula is :

\subsection{Adsorption Test of Organic Dyes}

$$
\frac{1}{2} \mathrm{Zn}\left(\mathrm{NO}_{3}\right)_{2} \cdot 6 \mathrm{H}_{2} \mathrm{O}+\frac{1}{2} 4,4^{\prime}-\mathrm{Bpy}+\mathrm{L}_{1}=\left[\left(\mathrm{Zn}_{0.5}\left(L_{1}\right)\left(4,4^{\prime}-\mathrm{Bpy}\right)_{0.5}\right)\right]+3 \mathrm{H}_{2} \mathrm{O}+2 \mathrm{HNO}_{3}
$$

\subsubsection{Adsorption performance test of methyl orange dyes}

Firstly, the standard curve of methyl orange was established, and then $5 \mathrm{mg}$ HU21 crystal was weighed, $40 \mathrm{mg} / \mathrm{L}$ methyl orange dye solution was collocated, $50 \mathrm{~mL}$ solution was taken for adsorption test, HU21 was put under visible light for adsorption performance test, and the absorbance test was carried out every 30 minutes with ultraviolet spectrophotometer, and the amount of adsorption was calculated. According to the relationship between dye concentration and absorbance, the absorbance can be expressed by adsorbent. ${ }^{[23]}$ The calculation formula is as follows:

$$
\mathrm{Q}=\frac{\mathrm{V}\left(\mathrm{C}_{0}-\mathrm{C}_{\mathrm{e}}\right)}{\mathrm{m}}
$$

Among them, Q is the amount of adsorption to be calculated, $\mathrm{V}$ is the volume of organic dye solution, $\mathrm{C}_{0}$ is the initial concentration of dye solution, $\mathrm{C}_{\mathrm{e}}$ is the concentration of dye solution after a certain time, and $\mathrm{M}$ is the mass of MOFs.

After that, the same volume of methyl orange dye solution was taken and put into $5 \mathrm{mg}$ HU21 crystal. Photocatalysis was carried out under xenon lamp. Absorption was measured after a certain time interval. The amount of adsorption was calculated. At the same time, the photocatalytic activity under xenon lamp was calculated. The calculation formula was as follows:

$$
\mathrm{D}=\frac{\mathrm{C}_{0}-\mathrm{C}_{\mathrm{e}}}{\mathrm{C}_{0}} \times 100 \%
$$

Among them, $\mathrm{D}$ is the catalytic rate to be calculated, $\mathrm{C}_{0}$ is the initial concentration of dye solution, $\mathrm{C}_{\mathrm{e}}$ is the concentration of dye solution after a certain time.

\subsubsection{Adsorption Performance Test of Methylene Blue}

Firstly, the standard curve of methylene blue was established, then the HU21 crystal was weighed $5 \mathrm{mg}$, the methylene blue dye solution was $25 \mathrm{mg} / \mathrm{L}$, the solution was $50 \mathrm{~mL}$ for adsorption test, the adsorption performance was tested under visible light, and the absorbance was tested with ultraviolet spectrophotometer every 30 minutes, and the amount of adsorption was calculated.

After that, methylene blue dye solution of the same volume was taken, and $5 \mathrm{mg}$ HU21 crystal was put into it. Photocatalysis was carried out under xenon lamp. Absorption test was carried out after a certain period of time. The amount of adsorption was calculated, and the photocatalytic efficiency under xenon lamp was calculated.

\section{Results and discussion}

\subsection{Crystal structure of HU21}

Single-crystal X-ray diffraction analysis revealed that HU21 crystallizes in monoclinic space group and a one-dimensional structure. The asymmetric unit consists of one half zinc ion, one $\mathrm{L}_{1}$ ligand, and one half 4,4'-Bpy molecule, as shown in Figure 1. The central metal $\mathrm{Zn}$ is 4 -coordinated as a square by two oxygen atoms from two $\mathrm{L}_{1}$ ligand and two nitrogen from two 4,4'-bipyridine ligands, respectively. Both the nito- and hydroxyl- functional groups of $\mathrm{L}_{1}$ ligands do not involve the coordination, thus $\mathrm{L}_{1}$ acts as the stick of the fishbone structure and prevent the vertical extension of the whole configuration.

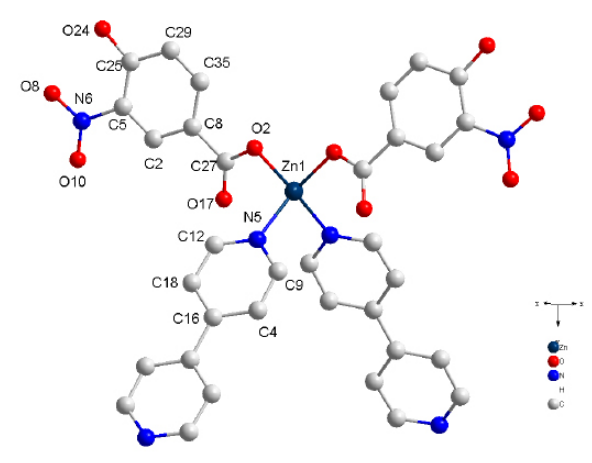

Figure 1 The asymmetric unit 
Figure 2 shows the chain structure of HU21. It can be seen that HU21 forms a chain structure through the alternate connection of asymmetric units.

Shown in Figure 3, the final superamolecular structure is formed by the $\pi-\pi$ stacking interaction of benzene rings between $\mathrm{L}_{1}$ ligands.

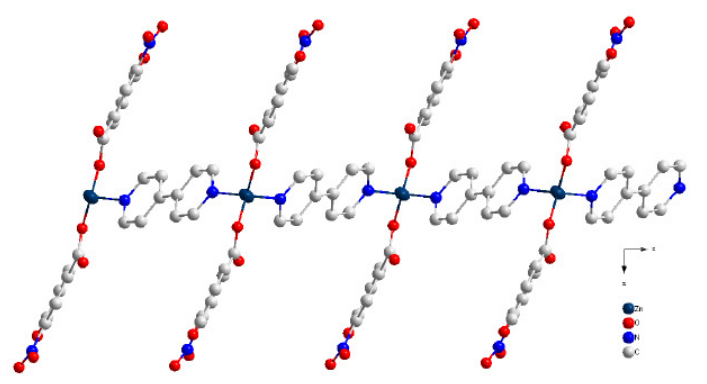

Figure 2 The chain structure of HU21

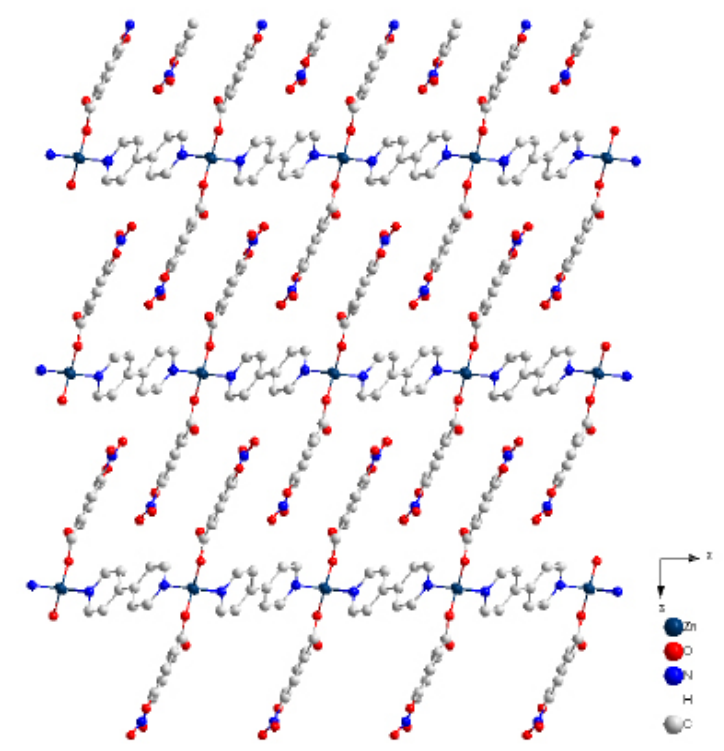

Figure 3 The three-dimensional structure of HU21

Table 1 shows the Crystallographic data of HU21.

\begin{tabular}{|c|c|}
\hline Conpound & {$\left[\mathrm{Zn}_{0.5}(\mathrm{~L} 1)\left(4,4^{\prime}-\mathrm{Bpy}\right)_{0.5}\right]$} \\
\hline Formula sum & $\mathrm{C} 24 \mathrm{H} 16 \mathrm{~N} 4 \mathrm{O} 10 \mathrm{Zn}$ \\
\hline Formula weight & $585.78 \mathrm{~g} / \mathrm{mol}$ \\
\hline Crystal system & monoclinic \\
\hline Space-group & $\mathrm{I} 12 / \mathrm{c} 1(15)$ \\
\hline $\mathrm{a}(\AA)$ & $14.0304(4)$ \\
\hline $\mathrm{b}(\AA)$ & $7.2705(2)$ \\
\hline $\mathrm{c}(\AA)$ & $22.4588(6)$ \\
\hline$\alpha\left(^{\circ}\right)$ & 90 \\
\hline$\beta\left(^{\circ}\right)$ & $92.46(0)$ \\
\hline
\end{tabular}

\begin{tabular}{|c|c|}
\hline$\gamma\left({ }^{\circ}\right)$ & 90 \\
\hline Cell volume $\left(\AA^{3}\right)$ & $2288.86(23)$ \\
\hline $\mathrm{z}$ & 4 \\
\hline Calc. density & $1.6998 \mathrm{~g} / \mathrm{cm}^{3}$ \\
\hline $\mathrm{F}(000)$ & 1192 \\
\hline $2 \theta \mathrm{max}\left({ }^{\circ}\right)$ & 70.457 \\
\hline index ranges $(\mathrm{h}, \mathrm{k}, \mathrm{l})$ & $-16 / 16$ \\
\hline & $-7 / 8$ \\
\hline & $-16 / 26$ \\
\hline reflections collected & 4184 \\
\hline $\mathrm{R}_{\text {int }}$ & 0.0293 \\
\hline data/restraints/parameters & $2031 / 0 / 178$ \\
\hline $\mathrm{GOF}\left(\mathrm{F}^{2}\right)$ & 1.086 \\
\hline $\mathrm{R}_{\mathrm{l}}, \mathrm{wR}_{2}[\mathrm{I} \geq 2 \sigma(\mathrm{I})]$ & $0.0565 / 0.1866$ \\
\hline $\mathrm{R}_{1}, \mathrm{wR}_{2}($ all date $)$ & $0.0598 / 0.1910$ \\
\hline
\end{tabular}

\subsection{Characterization of Adsorption Property}

\subsubsection{Characterization of adsorption properties of methyl orange}

Shown as Fig 4, the adsorption of methyl orange by HU21 under visible light and under xenon lamp irradiation. It can be seen that there is no adsorption effect when under visible light. Compared with visible light, HU21 adsorbs methyl orange better, but it can not absorb it completely.

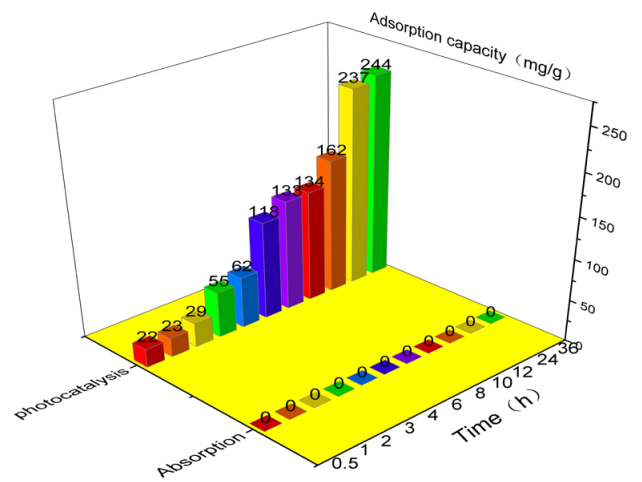

Figure.4( a )The adsorption capacity of HU21 to methyl orange.

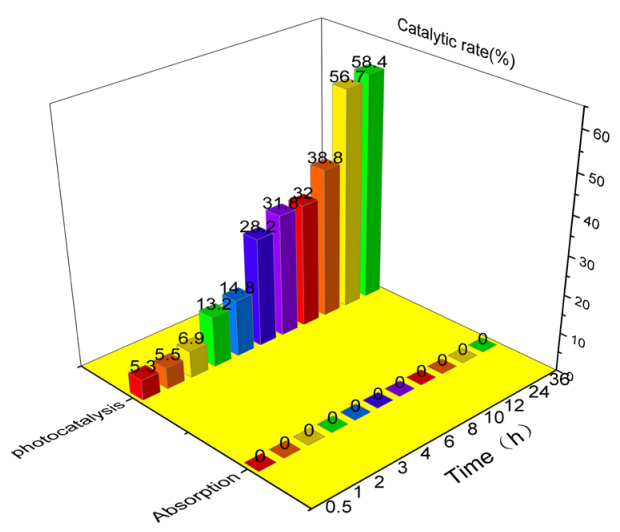

Figure .4(b)The catalytic rate of HU21 to methyl orange. 
Figure 5 (a) is a change in the absorbance of methyl orange after HU21 adsorbs methyl orange under xenon lamp irradiation.

Figure 5 (b) shows the catalytic activity of HU21 for methyl orange adsorption under xenon lamp irradiation. At 24 hours, the catalytic rate reached $56 \%$. Methyl orange is mainly decomposed into $\mathrm{CO}_{2}$ and hydrogen peroxide by $\mathrm{OH}$ produced by MOFs catalysis under the strong illumination of xenon lamp, which makes dye catalytic degradation.It can be seen that the absorption wavelength of the chromogenic group of methyl orange in the figure is $460 \mathrm{~nm}$. With the progress of photocatalysis, the absorption peak of the chromogenic group widens gradually, and the absorption wavelength moves to the left gradually. It

\section{(a)}

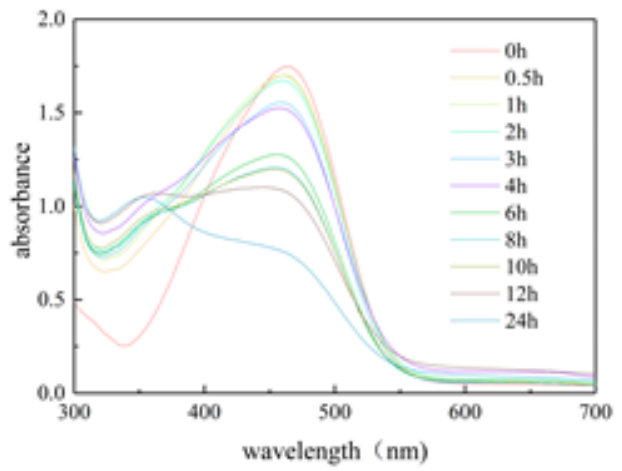

shows that the chromogenic group is degraded by HU21 catalysis, while the absorption near $300 \mathrm{~nm}$ rises because the decomposition product $\mathrm{CO}_{2}$ dissolves in water. It can be seen from the figure that the slope transformation of the catalytic rate curve of methyl orange is more frequent, which reflects the variation of the rate of holes and electrons produced by HU21.

\subsubsection{Characterization of Adsorption Properties of Methylene Blue}

Figure 6 shows the adsorption of methylene blue by HU21 under visible light and under xenon lamp irradiation. It can be seen that there is no adsorption effect when under visible light.

\section{(b)}

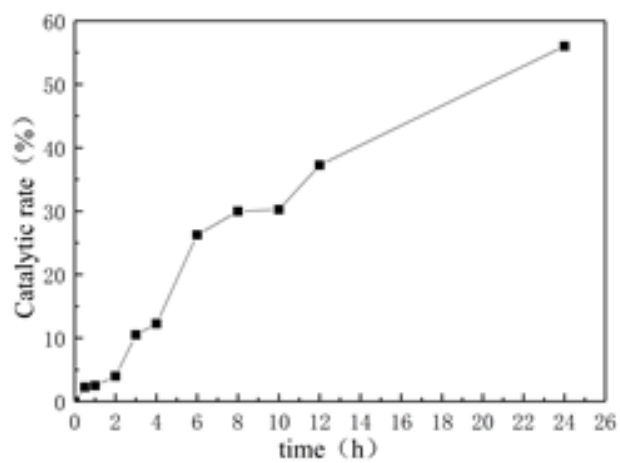

Figure 5 The absorbance of methyl orange after HU21 adsorbs methyl orange under xenon lamp irradiation(a).the catalytic activity of HU21 for methyl orange adsorption under xenon lamp irradiation. (b)

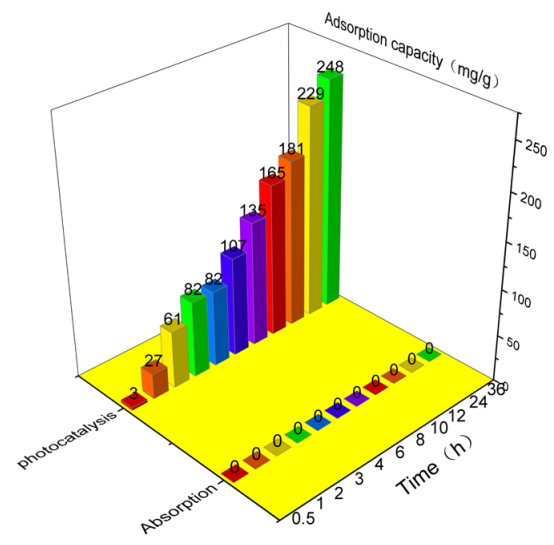

Figure .6(a)The adsorption capacity of HU21 to methylene blue.

Figure $7(a)$ is the change of absorbance of methylene blue after HU21 adsorbs methylene blue under xenon lamp irradiation. It can be seen that with the photocatalysis, the maximum absorption peak becomes wider and the absorption wavelength moves to the left gradually, which indicates that the chromogenic group of methylene blue is photocatalytically degraded by HU21, and the absorption wavelength shifts to the left with the gradual photocatalytic degradation. The increase of absorbance near $300 \mathrm{~nm}$ is due to the dissolution of decomposition product

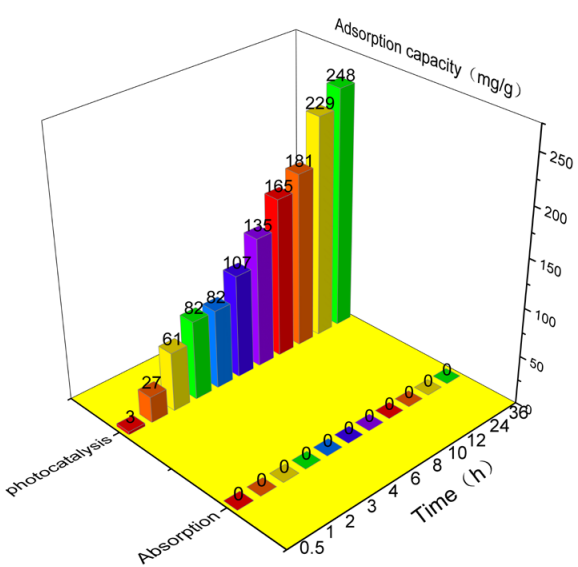

Figure .6(b)The catalytic rate of HU21 to methylene blue.

$\mathrm{CO}_{2}$ in water.

Figure 7(b) shows the catalytic activity of HU21 for methylene blue adsorption under xenon lamp irradiation. It can be seen that compared with the adsorption under visible light, the adsorption effect is greatly improved, the catalytic rate reaches $50 \%$ in only 8 hours, and after 32 hours, the catalytic rate is close to $100 \%$, showing superior photocatalytic performance. At the same time, we can also see that the slope of photocatalytic curve of methylene blue is larger in the early stage, and decreases grad- 
(a)

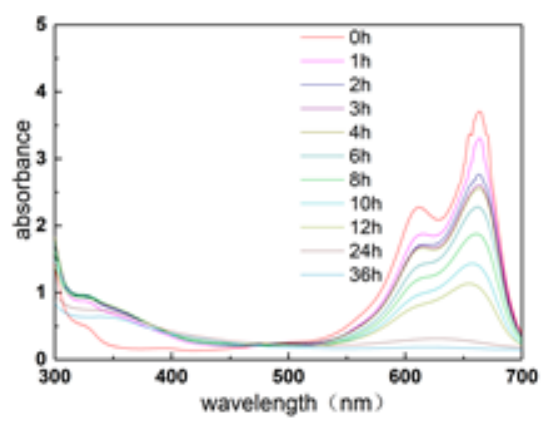

(b)

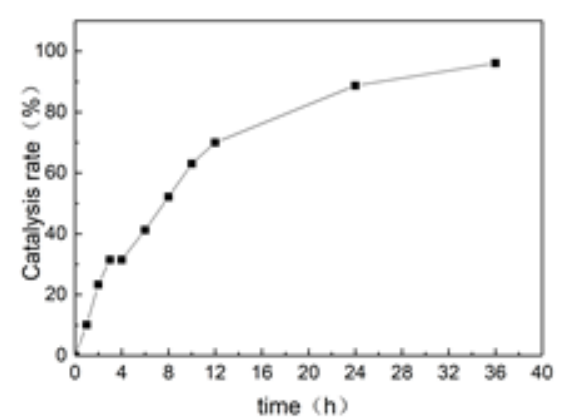

Figure 7 the absorbance of methylene blue after HU21 adsorbs methylene blue under xenon lamp irradiation.(a) the catalytic activity of HU21 for methylene blue adsorption under xenon lamp irradiation. (b)

ually with the time of photocatalysis.

Compared with the adsorption of methylene orange and methylene blue, it can be seen that although the photocatalytic rate of methylene blue dyes is higher, the adsorption amount of methylene blue and methylene orange is equal.

\section{Conclusions}

In this paper, we present a new structure of a MOFs HU21 $\left[\mathrm{Zn}_{0.5}\left(\mathrm{~L}_{1}\right)(4,4 \text { '-Bpy })_{0.5}\right]$ based on 4-hydroxy-3-nitrobenzoic acid and 4,4'-bipyridine skeleton, and characterize its dye adsorption and photocatalytic activity. Due to the poor porosity of HU21, hardly dye adsorption of methyl orange and methylene blue can be investigated in the dark. Under the strong illumination of xenon lamp, Zn-MOF depredates dye molecules to small molecules $\mathrm{CO}_{2}$ and $\mathrm{H}_{2} \mathrm{O}$. Although the adsorption amount of methylene blue and methyl orange were almost the same, HU21 displays a high photocatalytic rate on methylene blue.

\section{References}

[1]. Eddaoudi M, Kim J, Rosi N, Vodak D, Wachter J, O’Keeffe M, Yaghi OM: Systematic design of pore size and functionality in isoreticular MOFs and their application in methane storage. Science 2002, 295(5554):469-472.

[2]. Furukawa H, Ko N, Go YB, Aratani N, Choi SB, Choi E, Yazaydin AO, Snurr RQ, O'Keeffe M, Kim J et al: Ultrahigh Porosity in Metal-Organic Frameworks. Science 2010, 329(5990):424-428.

[3]. Millward AR, Yaghi OM: Metal-organic frameworks with exceptionally high capacity for storage of carbon dioxide at room temperature. Journal of the American Chemical Society 2005, 127(51):17998-17999.

[4]. Jin J-C, Wu J, Liu W-C, Ma A-Q, Liu J-Q, Singh A, Kumar A: A new Zn(II) metal-organic framework having 3D CdSO4 topology as luminescent sensor and photocatalyst for degradation of organic dyes. New Journal of Chemistry 2018, 42(4):2767-2775.

[5]. Liu K, Deng L, Li H, Bao Y, Xiao Z, Li B, Zhou Q, Geng $\mathrm{Y}$, Wang L: Two isostructural $\mathrm{Co} / \mathrm{Ni}$ fluorine-containing metal-organic frameworks for dye adsorption and supercapacitor. Journal of Solid State Chemistry 2019, 275:1-7.

[6]. Wu Y, Wu J, Luo Z, Wang J, Li Y, Han Y, Liu J: Fluorescence detection of $\mathrm{Mn} 2+$, Cr2O72- and nitroexplosives and photocatalytic degradation of methyl violet and rhodamine B based on two stable metal-organic frameworks. Rsc Advances 2017, 7(17):10415-10423.

[7]. Xue Z, Zhu M, Dong Y, Feng T, Chen Z, Feng Y, Shan Z, Xu J, Meng S: An integrated targeting drug delivery system based on the hybridization of graphdiyne and MOFs for visualized cancer therapy. Nanoscale 2019.

[8]. Rowsell JLC, Yaghi OM: Effects of functionalization, catenation, and variation of the metal oxide and organic linking units on the low-pressure hydrogen adsorption properties of metal-organic frameworks. Journal of the American Chemical Society 2006, 128(4):1304-1315.

[9]. Li Z-X, Hu T-L, Ma H, Zeng Y-F, Li C-J, Tong M-L, Bu X-H: Adjusting the Porosity and Interpenetration of Cadmium(II) Coordination Polymers by Ligand Modification: Syntheses, Structures, and Adsorption Properties. Crystal Growth \& Design 2010, 10(3):1138-1144.

[10]. Luo X, Mai Z, Lei H: A bifunctional luminescent Zn(II)-organic framework: Ionothermal synthesis, selective Fe(III) detection and cationic dye adsorption. Inorganic Chemistry Communications 2019, 102:215-220.

[11]. Chen W, Fan R, Wang P, Dong Y, Yang Y: Multifunctional Lanthanide-Based Metal-Organic Frameworks with a Polyheterotopic Ligand: Doped with Ytterbium(III) for Luminescence Enhancement and Selective Dye Adsorption. Chemistry-an Asian Journal 2018, 13(16):21262134.

[12]. Yan W, Han L-J, Jia H-L, Shen K, Wang T, Zheng H-G: Three Highly Stable Cobalt MOFs Based on "Y"-Shaped Carboxylic Acid: Synthesis and Absorption of Anionic Dyes. Inorganic Chemistry 2016, 55(17):8816-8821.

[13]. Zhang J, Li F, Sun Q: Rapid and selective adsorption of cationic dyes by a unique metal-organic framework with decorated pore surface. Applied Surface Science 2018, 440:1219-1226.

[14]. Zha Q, Sang X, Liu D, Wang D, Shi G, Ni C: Modification of hydrophilic amine-functionalized metal-organic frameworks to hydrophobic for dye adsorption. Journal of Solid State Chemistry 2019, 275:23-29.

[15]. Xu W, Chen Y, Kang J, Li B: Fabrication of ZIF-8 based on lignin with high yield for dye removal from water. Journal of the Iranian Chemical Society 2019, 16(2):385-392.

[16]. Han L-J, Ge F-Y, Sun G-H, Gao X-J, Zheng H-G: Effective adsorption of Congo red by a MOF-based magnetic material. Dalton Transactions 2019, 48(14):4650-4656. 
[17]. Luo Q, Zhu Z, Fan C, Zong Za, Xu C, Bi C, Fan Y: Two dia isomorphic Zn-MOFs based on two isomeric semi-rigid aromatic tetracarboxylate acids: Syntheses and properties. Journal of Molecular Structure 2019, 1188:57-61.

[18]. Xiao GB, Yao XQ, Xie H, Ma HC, Yan PJ, Qin DD: Dinuclear cobalt-based pillar-layered-like MOF as an electrode material for supercapacitor and photocatalysis activity. Polyhedron 2019, 162:39-44.

[19]. Qian L-L, Blatov VA, Wang Z-X, Ding J-G, Zhu L-M, Li K, Li $\mathrm{B}-\mathrm{L}, \mathrm{Wu} \mathrm{B}$ : Sonochemical synthesis and characterization of four nanostructural nickel coordination polymers and photocatalytic degradation of methylene blue. Ultrasonics Sonochemistry 2019, 56:213-228.

[20]. Yu D, Li L, Wu M, Crittenden JC: Enhanced photocatalytic ozonation of organic pollutants using an iron-based metal-organic framework. Applied Catalysis B-Environmental
2019, 251:66-75.

[21]. Zhu H, Liu D, Li Y-H, Cui G-H: Syntheses, crystal structures, and photocatalytic properties of two zinc(II) coordination polymers based on dicarboxylates and flexible bis(benzimidazole) ligands. Polyhedron 2019, 167:44-50.

[22]. Xiao J-D, Shang Q, Xiong Y, Zhang Q, Luo Y, Yu S-H, Jiang H-L: Boosting Photocatalytic Hydrogen Production of a Metal-Organic Framework Decorated with Platinum Nanoparticles: The Platinum Location Matters. Angewandte Chemie-International Edition 2016, 55(32):93899393.

[23]. Huo M, Yang W, Zhang H, Zhang L, Liao J, Lin L, Lu C: A new POM-MOF hybrid microporous material with ultrahigh thermal stability and selective adsorption of organic dyes. Rsc Advances 2016, 6(112):111549-111555. 